\title{
A Review of Main Factors Leading to Air Pressure Fluctuations in Branch Drainage Pipes inside Buildings
}

\author{
Rodger Millar Munthali, Xiangyang Huang* \\ Department of Water Supply and Drainage Science Engineering, School of Urban Construction, Jingzhou, China \\ Email: *mikecheng@126.com
}

How to cite this paper: Munthali, R.M. and Huang, X.Y. (2021) A Review of Main Factors Leading to Air Pressure Fluctuations in Branch Drainage Pipes inside Buildings. Journal of Building Construction and Planning Research, 9, 66-76.

https://doi.org/10.4236/jbcpr.2021.91006

Received: December 18, 2020

Accepted: March 26, 2021

Published: March 29, 2021

Copyright $\odot 2021$ by author(s) and Scientific Research Publishing Inc. This work is licensed under the Creative Commons Attribution International License (CC BY 4.0).

http://creativecommons.org/licenses/by/4.0/

\begin{abstract}
This paper is to discuss the main factors leading to the air pressure fluctuations in appliance branch pipes and measures to control them. It has been established that the main factors characteristics of a good sanitary pipework system are that it must prevent the transmission of foul air into the building, minimize blockages, provide efficient conveyance of discharge from sanitary appliances and minimize the risk of flooding to any part of a building. However, due to the nature and properties of sanitary appliance discharge, the flow being a three-phase flow which is simplified to two-phase for design computations and discharge being probabilistic, air variations in the horizontal appliance pipe result in phenomenon in which the sanitary network fails to perform as designed and installed to prevent or minimize aforementioned circumstances. It has been established that the main factors to be discussed leading to air pressure fluctuations in the appliance branch pipe are water traps, bend structures, pipe diameter, pipe slope and length, angle and connection mode and ventilation conditions. These factors' associated control measures have also been presented. However, factors pertaining to concentration of appliance discharge have not been discussed. The result of this discussion will enable designers and installers of sanitary pipework to incorporate measures to control air pressure fluctuations in appliance branch pipes inside buildings.
\end{abstract}

\section{Keywords}

Drainage Stack, Sanitary Appliance, Sanitary Pipework, Water Trap, Transients

\section{Introduction}

In building drainage systems, the prevention of cross-contamination is an abso-

${ }^{*}$ Corresponding author. 
lute necessary to protect against both infection spread and odor ingress [1] [2]. The importance of a good drainage system on protecting public health became evident after it was discovered that the drainage system contributed to the spread of Severe Acute Respiratory Syndrome (SARS) in 2003 in Hong Kong [3] [4]. Recent studies have shown aerosolized bacteria can be carried by the building drainage system airflows into the living space due to excessive air pressures [5]. Therefore, a good sanitary pipework system should be designed and installed to ensure that: there is no transmission of foul air into the building; the frequency of any blockage is minimal, and provides with adequate pipe access to enable the effective clearance of any such blockage; it provides efficient conveyance of discharge from sanitary, kitchen, laundry and wash-down facilities, to enable the correct function of each appliance; and, where any sewer is likely to surcharge, the risk of flooding to any part of a building where the floor level is located below normal ground level is of concern [6]. However, air pressure variations in the horizontal drainage stacks make this undertaking a challenge; hence, there is the need for control [7] [8].

To be able to effectively develop measures to control air pressure fluctuations in appliance branch pipes inside buildings, this research article identifies and discusses the main factors leading to the air pressure fluctuations in appliance branch pipes and measures taken to prevent them entry.

This paper first gives an overview of BDS in Literature, in which the nature components of the system and nature of flow are given. The methods used to identify the main factors are discussed next, followed by results and discussion. In results and discussion, the factors are discussed first followed by the measures to control the air pressure fluctuations.

\section{Literature Review}

The sanitary pipework design has a drainage stack (vertical pipe) component and a branch stack (horizontal pipe) component. The branch stack, which is of focus in this paper, conveys discharge from the discharge unit or appliance to the stack (riser) connected at a branch. The characteristics of sanitary ware drainage are probabilistic drainage, in that they depend on the randomness of using sanitary appliances such as WCs, sinks, baths, showers and washing machines [2] [9] [10]. The drainage contains debris and paper scraps. In the drainage process, it also carries a lot of air with varying pressures. The actual water flow is in the state of three-phase flow of water, air and solid [10] [11]. However, the solid flow is small hence the flow is simplified into intermittent non-uniform flow of water and gas. The study of the two-phase flow of water and gas in the drainage system is the basis for the rational design of the drainage system of high-rise buildings [1] [8]. The water flow motion of the horizontal drainage pipe is a complex, non-stable and non-uniform flow with compressible gas [1].

In order for the sanitary pipework to be able to prevent the transmission foul air in to the building, and other harmful gases, generated in the drainage pipe- 
line from entering the room and polluting the environment, a trap or water seal is installed at the outlet of the sanitary appliance [1] [6] [12]. The purpose of a waste trap is to provide a water seal between the waste water pipework and the internal environment of the property, thus stopping any foul air entering the building which would be both hazardous and unpleasant [13]. This water seal must be protected to prevent the ingress of polluted air into the living environment. The water trap seal, which has a depth of between $50 \mathrm{~mm}$ and $75 \mathrm{~mm}$, is located immediately downstream of a discharge unit [14] or incorporated into the discharge unit [1].

Air pressure variations in Building Drainage Systems (BDS) typically arise from a change in fluid flow conditions of the stack and branch discharge and these air pressure fluctuations are known to induce siphoning effects and positive pressures which lead to depletion of the water seals [4] [7] [15]. It has been experimentally demonstrated that lower frequency air pressure fluctuations in the drainage stack are associate with a greater trap seal displacement [16]. Some of the factors affecting the air pressure fluctuations in the appliance branch pipes include water seal type, type and size of bend structure, pipe diameter, pipe slope and length, angle and connection mode and ventilation conditions.

\section{Materials and Methods}

The research mainly involves literature review in the field of drainage inside buildings for subsequent discussion. All literature published to 2020 in the field of building drainage was bound to be selected for inclusion, as there was no filter for year of publication, with the focus being air pressure fluctuations in drainage stacks inside buildings. Initial search terms were derived from authors' knowledge of sanitary pipe networks. Using these search terms searches were conducted in literature databases, with keywords obtained from successive obtained literature adding to the list of search terms. Table 1 below summarizes the initial and subsequent search terms and phrases.

After gathering the literature from peer-reviewed journals and books by searching in such databases as Google Scholar, Elsevier, Google and Bing, the main factors contributing to air pressure fluctuations in drainage pipes inside buildings were identified through frequency as these factors kept on appearing in journal articles, books and conference proceedings. Table 2 below presents

Table 1. Main search terms and phrases.

\begin{tabular}{|c|c|c|}
\hline & Author Generated Terms and Phrases & Keywords and Phrases from Literature \\
\hline 1 & Horizontal drainage pipes inside buildings & Branch pipe, drainage inside buildings, stack, branch pipes \\
\hline 2 & Building drainage design & Discharge branch pipe, sanitary pipework \\
\hline 3 & Transients in horizontal pipes & Air pressure fluctuations in branch pipe, \\
\hline 4 & Water supply and drainage for buildings & Drainage capacity, water traps, induced siphonage, trap seal, \\
\hline 5 & Water seals, trap, seal loss prevention & $\begin{array}{l}\text { Loss of water seal, Positive Air Pressure } \\
\text { Attenuators (P.A.P.A), Air Admittance Valves (A.AV) }\end{array}$ \\
\hline
\end{tabular}


Table 2. Main sources used.

\begin{tabular}{|c|c|c|c|}
\hline & Journal Articles & Books & Conference Proceedings \\
\hline 1 & $\begin{array}{l}\text { Wong, L. T. Mui, K. W. Hui, P. } \\
\text { S (2008) [7] }\end{array}$ & $\begin{array}{l}\text { Hall and Greeno } \\
\quad(2015)[17]\end{array}$ & $\begin{array}{c}\text { Baron B.T., Oliveira L.H., Comas } \\
\text { F.N., Ota, I.R. (2018) [10] }\end{array}$ \\
\hline 2 & Cheng, Yen and He (2008) [18] & Swaffield (2010) [2] & $\begin{array}{l}\text { Daniel W.T. Chan, Leo K.C. Law and } \\
\text { Eric S.W. Wong (2006) [12] }\end{array}$ \\
\hline 3 & $\begin{array}{l}\text { Cheng-Li, Cheng, Wen-Hung } \\
\text { Lu, Ming-Der Shen (2005) [8] }\end{array}$ & $\begin{array}{c}\text { Chardertton (2007) } \\
{[19]}\end{array}$ & Swaffield, J. A. (2004) [14] \\
\hline 4 & $\begin{array}{l}\text { CL Cheng, CJ Yen, LT Wong } \\
\text { KC Hoa (2008) [11] }\end{array}$ & $\begin{array}{l}\text { Wise and Swaffield } \\
\text { (2002) [20] }\end{array}$ & Wong, L. T. Mui, K.W. (2006) [4] \\
\hline
\end{tabular}

the many sources used in the review.

The next step was to review specific factors and get perspectives from all journals articles and books by way of cross-referencing.

\section{Results and Discussion}

The section presents the results from the study. First is a discussion of the results of factors affecting Air Pressure fluctuations in branch drainage pipes followed by a discussion of the measures currently being employed to control these air pressure fluctuations.

\subsection{Factors Influencing Air Pressure Fluctuations}

From the study, it has been established that the main factors leading to air pressure fluctuations in the appliance branch pipe are water traps, bend structures, pipe diameter, pipe slope and length, angle and connection mode and ventilation conditions.

\subsubsection{Bends and Traps}

Self-siphonage occurs when the appliance discharge has enough momentum to carry the trap seal out into the connected branch [2]. As such the types and number of bends in branch discharge types has a bearing on the behavior of air pressure in the system, hence limitations on the type and number of bends are specified [21] [22]. Most baths and some sinks do not normally give trouble from this action. Their shapes are such as to cause a considerable slowing down of flow and the formation of a vortex as they empty, giving a long 'trailing discharge' from the flat bottom after the main discharge. The usual result is that, although a strong self-siphonage action in the waste pipe may reduce the trap seal, any loss of water is eventually replenished by the long trail. A few tests conducted by Wise in 1955 confirmed this and indicated that baths and large sinks can safely be installed without vents in many circumstances. The situation is different with small or bowl-shaped appliances in which a fairly high rate of dis-charge is maintained throughout and little trailing water remains at the end. Wash basins, in particular, give this type of discharge and may lose all their seal by self-siphonage in extreme circumstances. Water closets also can be self-siphoned 
but this is not a problem in normal installations because the large branch pipe runs directly to the stack with only one or two bends and the full-bore flow necessary to cause self-siphonage does not develop. Water closets, therefore, do not usually need a vent pipe so far as self-siphonage is concerned, and so wash basins are the only appliances requiring special study in this respect [23].

On the types of traps, compared with P-shaped water-holding bend, S-shaped water-holding bend is easier to form self-siphoning, and water seal loss is usually greater than p-shaped bend. In terms of diameters, reducing water storage bend with smaller outlet diameter has greater water seal loss compared with equal diameter water storage bend as shown in Figure 1 below [1].

\subsubsection{Discharge Pipeline Slope}

When the slope of branch discharge pipe is small, local negative pressure is generated near the stack, as shown in Figure 2 which may cause seal loss as the plug flow moves down the branch pipe. After the discharge of the appliance, the movement of the water plug causes pressure fluctuation, and the water seal is slightly lost [23].

With a slight increase in slope, a hydraulic jump occurs near the drainage riser, as shown in Figure 3.

A negative pressure of $50 \mathrm{~mm}$ is generated in the transverse tube for Figure 3 . After the discharge of the appliance, the hydraulic jump surface moves upstream under the action of negative pressure inside the tube, but fails to reach the water

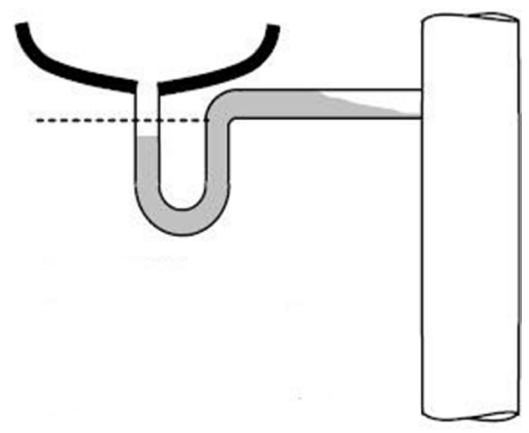

Figure 1. Self-siphonage, discharge momentum sufficient to empty trap, no stack flow necessary (adapted from reference [2]).

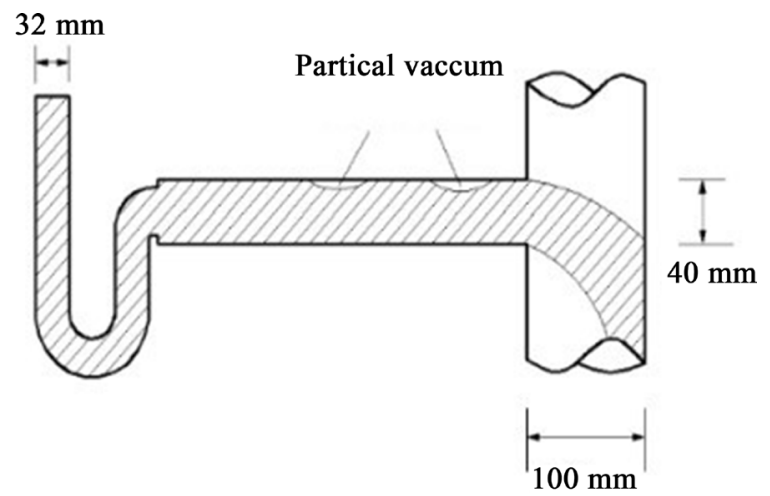

Figure 2. When branch discharge pipe slope is small (adapted from reference [1]). 
trap. The negative pressure eventually rises to $60 \mathrm{~mm}$, resulting in a large water seal loss [1].

As the slope continues to increase, the same hydraulic jump occurs near the stack. Due to the large slope, the hydraulic jump moves slowly downstream to reach the stack before the end of drainage of the appliance, as shown in Figure 4 [1].The partial vacuum is relieved and there is no suction on the trap at the end of the flow, the seal remains full [23].

Sanitary discharge pipework should therefore be designed and installed with adequate gradient [6].

\subsubsection{Diameter of Stack (Vertical Pipe)}

When the diameter of the discharge stack is large, the full pipe flow is not formed in the horizontal branch pipe, as shown in Figure 5.

At this point the pressure is stable and there is no loss of water seal. However, when the size of the riser is small the water flow is blocked at the connection

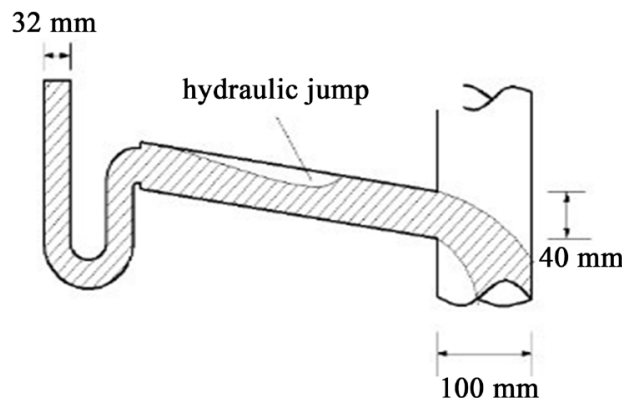

Figure 3. When branch pipe discharge is slightly large (adapted from reference [1]).

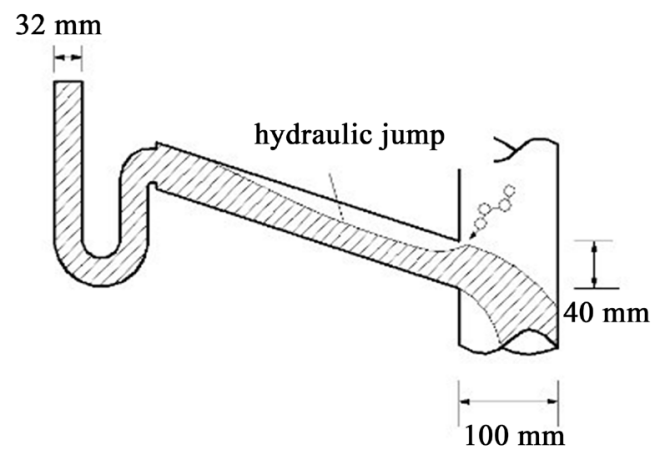

Figure 4. When branch pipe discharge is large (adapted from reference [1]).

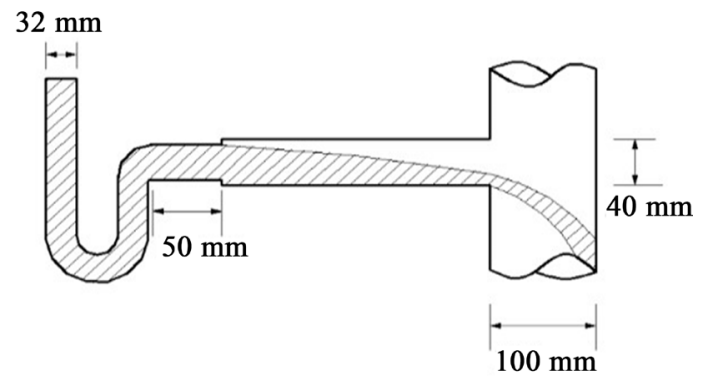

Figure 5. Large diameter of discharge stack (adapted from reference [1]). 
between the horizontal pipe and the stack. Backwater results in the formation of positive pressure above $40 \mathrm{~mm}$ in the transverse pipe at first, followed by hydraulic jump and negative pressure below $60 \mathrm{~mm}$, as shown in Figure 6. Kimura et al. [24] found out through experiments that maximum negative pressure becoming higher as the pipe diameters increase.

The air pressure in the horizontal pipe fluctuates violently and the water seal loss is great.

When the slope is very small, the negative pressure may make the water flow back to the reservoir bend, reducing the water seal loss [1] [6].

\subsubsection{Pipe Length and Connection Mode}

The effect of the pipe length is that the longer the branch pipe is, the greater the water seal loss caused by pressure fluctuation in the pipe is, as shown in Figure 7.

The connection mode also has a certain influence on the pressure fluctuation of the drainage pipe [1]. The type of connection between the vertical stack and horizontal drain potentially causes a hydraulic jump which is capable of creating a positive pressure and very possibly lead to the depletion of the seal on an upper

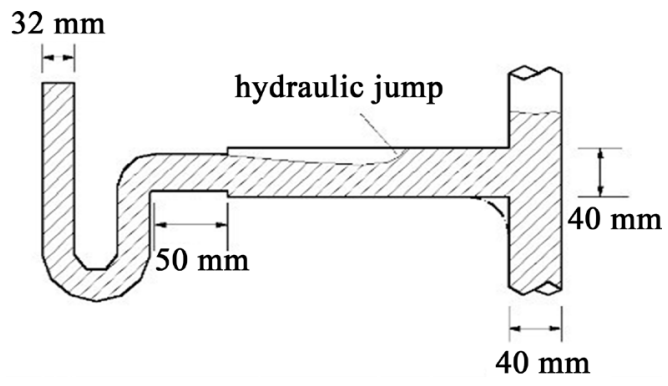

Figure 6. Smaller diameter of discharge stack (adapted from reference [1]).

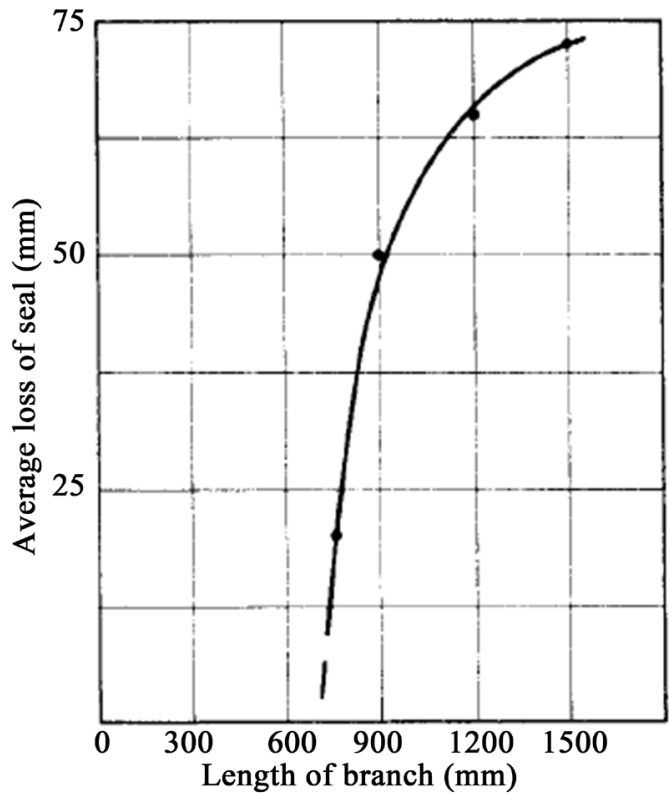

Figure 7. Example of effect of pipe length on seal loss for $32 \mathrm{~mm}$ trap and pipe (adapted from reference [20]). 
floor. Therefore, the Connection Method (C.M) is important for performance evaluation in high-rise building drainage system design. The C.M mainly focuses on the position from vertical stack to horizontal drain but should also be known that pressure fluctuation caused by a $90^{\circ} \mathrm{DC}$ pipe fitting is larger than that caused by a downstream pipe fitting [1] [18] [22].

\subsubsection{Ventilation Status}

Induced siphonage occurs when discharge from one appliance draws out the seal in the trap of an adjacent appliance [17]. This is as a result of vacuum being formed in adjacent appliance branch and depleting the water seal in the process. It is as a result of a poorly ventilated drainage system. It is reasonable to assume that the horizontal drains should not flow more than half full to provide greater safety margin against surcharge in the branches from appliances. When this is not respected pressure fluctuations may be caused as a result of self-siphoning and induced siphoning [1].

\subsection{Measures to Control Air Pressure Fluctuations}

There are several ways to control or minimize air pressure fluctuations, consequently preventing water seal depletion and ingress of odor into the habitable space. The measures, insomuch as they relate to the factor leading to the air pressure fluctuation, they relate to the design of the drainage system, and some of the measures are presented.

Relating to the seal depth, with a minimum water depth of $50 \mathrm{~mm}$, several international and local standards specify $\pm 375 \mathrm{~N} / \mathrm{m}^{2}$ as the maximum pressure to avoid the water seal from being sucked into the branch stack or pushed into the appliance, leading to its depletion. These standards include BS EN 12056-2:2000 and GB50015-2003 (2009) [1] [2] [19] [21]. At the specified seal depth and pressure, the water seal will retain the minimum depth to allow for evaporation and self-siphonage [20].

In Figure 6, the positive and negative pressure formed by backwater in the transverse branch pipe and the riser pipe can be alleviated to a certain extent if a smooth water pipe fitting with good hydraulic conditions is adopted at the connection between the transverse branch pipe and the riser pipe [1] [19] [20].

In addition, by comparing Figure 2 and Figure 5, it can be found that, compared with the immediate enlargement of pipe diameter at the outlet end of water storage bend, the connection mode of pipe diameter enlargement after passing through a $50 \mathrm{~mm}$ transverse pipe at the outlet end of water storage bend is more difficult to form full pipe flow, and the pressure fluctuation in the transverse pipe is small [1] [6]. CIBSE Guide G [25] advises connecting larger or equal diameter branch waste pipes to the discharge stack with swept or branches having a $45^{\circ}$ slope to maintain laminar flow.

The appliance ventilation pipe can directly connect the positive and negative pressure area inside the pipe with the atmosphere to reduce the pressure fluctuation inside the pipe. Ventilated branches allow free movement of air and ingress 
of air to relieve pressures developed during operation. Table 9 of BS EN: 12056-2 specifies the connection modes, number of appliances, gradient of and length of branches and number of offsets [25]. In addition, the setting of suction valve also helps to relieve the negative pressure in the pipe, but does not have any effect on the positive pressure. For safety, the suction valve should be set vertically where the air is flowing [1].

The number and nature of bends as discussed contribute to air pressure fluctuations in drainage pipes. Therefore, sanitary discharge pipework should be designed and installed with few bends. In addition, they should have adequate gradient to prevent surcharging the water seals but permitting air flow [6]. According to England Building Regulations approved document $\mathrm{H}$, for a drainage system conforming to standards, separate ventilation is not necessary [22].

To prevent self-siphonage and induced siphonage, Air Admittance Valves (AAV) are installed to admit air, as the negative pressure is as a result of lack of air in the system. One example of such valve is the Positive Air Pressure Attenuator (P.A.P.ATM) [26]. A Positive Air Pressure Attenuator (P.A.P.A) may be used successfully to control and suppress positive transients [2]. Gormley and Kelly [5] demonstrate that a device, located in line with the drainage stack is effective at suppressing air pressure transients.

\section{Conclusions}

A Building Drainage System (BDS) must ensure that the health of individuals occupying the building it serves is safeguarded. However, air pressure fluctuations in the branch stack result in water seal loss, which can result in ingress of foul air into the living space from the sanitary pipework. This paper has thus discussed the main factors leading to air pressure fluctuations in appliance branch pipes so that designers and installers can develop measures to control air pressure fluctuations in appliance branch pipes in buildings. The review involved identifying overarching factors in different journal articles, books, conference proceedings and standards. It has been identified that these factors are traps or water seals, diameter of drainage pipe, length of branch stack and connection mode of the branch pipe to stack, ventilation status of the branch stack.

More research needs to be conducted to ascertain the effects of detergents, frequency of discharge and capacity of discharge appliances on the air pressure fluctuations in the horizontal drainage pipes.

\section{Conflicts of Interest}

The authors declare no conflicts of interest regarding the publication of this paper.

\section{References}

[1] Qiongxian, K. (2020) Drainage Systems of High-Rise Buildings. Yangtze University, Jingzhou. 
[2] Swaffield, J. (2010) Transient Airflow in Building Drainage Systems. Spon Press, London. https://doi.org/10.4324/9780203879757

[3] Wong, E.S.W., Chan, D.W.T., Jones, P. and Law, L.K.C. (2008) Assessment of Air Pressure inside a Drainage Stack. Proceedings of the International Multi-Conference of Engineers and Computer Scientists, Hong Kong, 19-21 March, 2008, 1534-1539.

[4] Wong, L.T. and Mui, K.W. (2006) A Case Study of Air Pressure Fluctuations in Drainage Stacks of High-Rise Residential Buildings. CIB, Taipei, 1-8.

[5] Gormley, D.A.K.M. (2017) Air Pressure Transient Generation, Propagation and Alleviation in Tall Buildings. Proceedings of the 43 rd International Symposium of CIB W062 Water Supply and Drainage for Buildings, Haarlem, 23-25 August 2017, 325-338.

[6] T. I. o. Plumbing (2002) Plumbing Engineering Services Design Guide. Vol. 44, The Institute of Plumbing, Essex.

[7] Wong, L.T., Mui, K.W. and Hui, P.S. (2008) Air Pressure Variations at Drainage Stacks of High-Rise Residential Buildings. Facilities, 26, 463-469.

https://doi.org/10.1108/02632770810895723

[8] Cheng, C.-L., Lu, W.-H. and Shen, M.-D. (2005) An Empirical Approach: Prediction Method of Air Pressure Distribution on Building Vertical Drainage Stack. Journal of the Chinese Institute of Engineers, 28, 205-217. https://doi.org/10.1080/02533839.2005.9670988

[9] Gormley, M. and Kelly, D.A. (2019) Pressure Transient Suppression in Drainage Systems of Tall Buildings. Building Research and Information, 47, 421-436. https://doi.org/10.1080/09613218.2017.1412097

[10] Baroni, B.T., Oliveira, L.H., Comas, F.N. and Ota, I.R. (2018) Drain Diameter Reduction in a Two-Storey Residential Building Drainage System for Optimised Performance to Water Conservation. Proceedings of 44 th International Symposium CIB W062 on Water Supply and Drainage for Buildings, Ponta Delgada, 28-30 August 2018, 10-16.

[11] Yen, C.J., Cheng, C.L., Wong, L.T. and Hoa, K.C. (2008) An Evaluation Tool of Infection Risk Analysis for Drainage Systems in High-Rise Residential Buildings. Building Services Engineering Research and Technology, 29, 233-248. https://doi.org/10.1177/0143624408091448

[12] Chan, D.W.T., Law, L.K.C. and Wong, E.S.W. (2006) Problem of Air and Water Backflow in High-Rise Building Drainage System. CIB, Taipei.

[13] P. B. Products (2011) Technical Installation Guide: Above \& below Ground Drainage. Polypipe.

[14] Swaffield, J.A., Jack, L.B. and Campbell, D.P. (2004) Control and Suppression of Air Pressure Transients in Building Drainage and Vent Systems. CIB, Paris, 459-470.

[15] Swaffield, J.A. (2006) Sealed Building Drainage and Vent Systems-An Application of Active Air Pressure Transient Control and Suppression. Building and Environment, 41, 1435-1446. https://doi.org/10.1016/j.buildenv.2005.08.011

[16] Cheng, C.L., Mui, K.W., Wong, L.T., Yen, C.J. and He, K.C. (2010) Characteristics of Air Pressure Fluctuations in High-Rise Drainage Stacks. Building and Environment, 45, 684-690. https://doi.org/10.1016/j.buildenv.2009.08.006

[17] Hall, F. and Greeno, R. (2015) Building Services Handbook. Routledge, London. https://doi.org/10.4324/9781315752129

[18] Cheng, C.L., He, K.C. and Yen, C.J. (2008) Decision-Making and Assessment Tool for Design and Construction of High-Rise Building Drainage Systems. Automation 
in Construction, 17, 897-906. https://doi.org/10.1016/j.autcon.2008.04.005

[19] Chaddertoni, D.V. (2007) Building Services Engineering. Taylor \& Francis, Abingdon-on-Thames. https://doi.org/10.4324/9780203962992

[20] Wise, E. and Swaffield, J.A. (2002) Water, Sanitary and Waste Services for Buildings. Butterworth-Heinemann, Oxford.

[21] B. S. Institute (2000) BS EN 12056-2:2000 Gravity Drainage Systems inside Building Part 2: Sanitary Pipework, Layout and Calculation. British Standards Institute, London.

[22] B. Regulations (2015) Approved Document H: Drainage and Waste Disposal. Drainage and Waste Disposal. NBS, London.

[23] Wise, A.F.E. (1955) Self-Siphonage in Building Drainage Systems. Proceedings of the Institution of Civil Engineers, 3, 789-808.

https://doi.org/10.1680/ipeds.1954.12600

[24] Kimura, K., Sakaue, K., Mitsunaga, T., Inada, T., et al. (2016) A Study on Characteristics of Siphonic Drainage Systems with Extra Small Diameter Piping. Proceedings of the 42 nd International Symposium of CIB W062 on Water Supply and Drainage for Buildings, Kosice, 29 August-1 September 2016, 161-170.

[25] T. C. I. o. B. S. Engineers (2014) CIBSE Guide G: Public Health and Plumbing Engineering. CIBSE, London.

[26] White, S. and Hill, A. (2015) High-Rise Testing of Active Drainage System Compared with Conventional Venting on Two Test Towers. Proceedings of the 41 st International Symposium of CIB W062 on Water Supply and Drainage for Buildings, Beijing, August 2015, 11-29. 